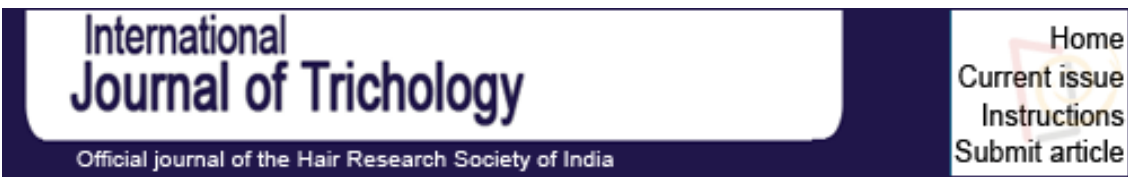

Int J Trichology. 2013 Jul-Sep; 5(3): 151-153.

PMCID: PMC3927175

doi: $10.4103 / 0974-7753.125616$

\title{
Perifollicular Erythema as a Trichoscopy Sign of Progression in Frontal Fibrosing Alopecia
}

Tomás Toledo-Pastrana, María Jasé García Hernández, ${ }^{1}$ and Francisco M Camacho Martínez

Dermatology Unit, Virgen Macarena University Hospital, Spain

${ }^{1}$ University of Seville Medical School, Seville, Spain

Address for correspondence: Dr. Tomás Toledo-Pastrana, Dermatology Unit, Hospital Virgen Macarena University Hospital, Avda. Dr. Fedriani S/N, 41071 Seville, Spain. E-mail: ttoledop@gmail.com

Copyright : ( I) International Journal of Trichology

This is an open-access article distributed under the terms of the Creative Commons Attribution-Noncommercial-Share Alike 3.0 Unported, which permits unrestricted use, distribution, and reproduction in any medium, provided the original work is properly cited.

This article has been cited by other articles in PMC.

\section{Abstract}

\section{Introduction:}

Frontal fibrosing alopecia (FFA) in an entity characterized by the recession of the frontotemporal hairline (FTHL) with alopecic scarring change. In recent years there are numerous articles discussing the usefulness of dermoscopy for the clinical diagnosis of different types of scarring alopecia.

\section{Materials and Methods:}

We value 79 patients diagnosed with FFA, evaluating some trichoscopical findings described as typical for FFA: Absence of follicular opening, follicular hyperkeratosis, follicular plugs and erythema.

\section{Results:}

In a population of 79 women, $100 \%$ showed no follicular opening, $72.1 \%$ follicular hyperkeratosis, $66.3 \%$ perifollicular erythema and $44.8 \%$ follicular plugs. Thus, $100 \%$ of patients had at least one of the dermoscopic elements described as suggestive of FFA, 53\% two of them, $45 \%$ three and $27 \%$, all those elements. Perifollicular erythema was present in $95 \%$ of cases in which the disease was active.

\section{Conclusions:}

We consider that the presence of perifollicular erythema will be a direct marker of FFA activity.

Keywords: Dermoscopy, diagnosis, frontal fibrosing alopecia, pattern

\section{INTRODUCTION}

Frontal fibrosing alopecia (FFA) in an entity characterized by the recession of the frontotemporal hairline (FTHL) with alopecic scarring changes, usually accompanied by alopecia in other non-scalp locations. Initially defined as a disease appearing only in postmenopausal women, no hormonal status association was later proven.[1] However, the rest of FFA clinical manifestations such as axillar or eyebrow alopecia, lichen planopilaris, or pruritus appear in a variable frequency, except for the mentioned recession of the hairline present in all patients.[2]

In recent years, there are numerous articles discussing the usefulness of trichoscopy for the clinical 
diagnosis of different types of scarring alopecia,[3] having found this technique as useful in the differential diagnosis of certain diseases, such as alopecia areata (AA). The presence of scarring changes, perifollicular papules, yellow and black points and vascular loops as the absence of follicular opening describe a pattern that could be defined as characteristic for that disease.[4]

Founded on that appreciation, we consider that it would be useful to describe some constant dermoscopic findings in FFA and if the presence of those findings defines a diagnostic pattern.

\section{MATERIALS AND METHODS}

Go to:

We value 79 patients diagnosed with FFA in the Department of Dermatology of the Virgen Macarena University Hospital in Seville, Spain, from March 2010 to May 2012. All of them carried a minimum follow-up period of 12 months, with three monitoring visits every 3 months, where a dermoscopic photographic control was taken using a canon 450D camera connected to a DermLite ${ }^{\circledR}$ handheld II hybrid m dermatoscope, (3Gen, LLC, San Juan Capistrano, CA, USA, magnification $\times 10$ ). Furthermore, all patients performed the same treatment, consisting of a monthly intralesional infiltration of $10 \mathrm{mg} / 1 \mathrm{ml}$ triamcinolone acetonide ( $1 \mathrm{ml} / \mathrm{injection})$ plus twice daily topic application of $5 \%$ minoxidil alcoholic solution and $0.025 \%$ clobetasol propionate cream plus $1 \mathrm{mg} /$ day of finasteride $\mathrm{per}$ os. The treatment was maintained for 12 months.

A descriptive observational study was performed considering as variables sex, age and dermoscopic findings described in the literature as typical for FFA: Absence of follicular opening, follicular hyperkeratosis, follicular plugs and erythema. It was also determined if the disease was on an active or inactive phase for each patient in every visit, measuring the receding of the FTHL in centimeters. The qualitative variables were analyzed using the Chi-square test, with application of the Student $t$-test for quantitative variables, after confirming normal distribution with the Shapiro-Wilk test.

We did not consider the presence of other dermoscopic elements as dystrophic hairs, as these are a common finding in any scarring alopecia.

All data were analyzed using SPSS 15.0 version (SPSS Inc., Chicago, IL, USA).

\section{RESULTS}

In a population of 79 women with a mean age of 56.8 years (range: $42.6-71.3$ ), $100 \%$ showed no follicular opening, $72.1 \%$ follicular hyperkeratosis, $66.3 \%$ perifollicular erythema and $44.8 \%$ follicular plugs. Thus, $100 \%$ of patients had at least one of the dermoscopic elements described as suggestive of FFA, $53 \%$ two of them, $45 \%$ three and $27 \%$, all those elements.

We also appreciated that perifollicular erythema was present in $95 \%$ of cases in which the disease was active, being this the only element of the pattern that reached statistically significant differences between the two groups (active vs. inactive disease), $(P<0.01)$. Patients with erythema also showed greater recession of FTHL than those who did not have erythema $(5.1 \mathrm{~cm}$ vs. $3.6 \mathrm{~cm}, P<0.05)$ [Table 1 ].

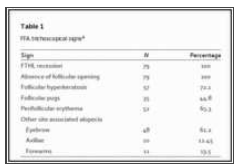

Table 1

FFA trichoscopical signs ${ }^{\mathrm{a}}$

\section{DISCUSSION}

Trichoscopy has been shown helpful for the diagnosis of FFA in our series, primarily to establish differential diagnosis between different types of scarring alopecia.[5] As already was pointed by other authors, the presence of certain dermoscopic findings can settle a characteristic diagnostic pattern versus other alopecic disorders, such as AA,[5] this situation does not occur in FFA, basically because the diagnosis is based on clinical appreciations, mainly on the presence of a receding FTHL.[6] However, the presence of typical dermoscopic findings would describe a typical diagnostic pattern, as 
some authors have recently referred,[, $\underline{7}, \underline{9}]$ but can be also useful to assess if the disease is active or not or if the prescribed treatment is being advantageous.[10,11] In our series, the trichoscopical findings in FFA include absence of follicular openings, follicular hyperkeratosis, perifollicular scaling and perifollicular erythema.[12, $\underline{13}]$ Perifollicular scaling is better appreciated with the use of polarized dry trichoscopy[14] [Figure 1]. Broken hair shafts and pili torti can be seen occasionally too. Perifollicular erythema is a characteristic feature of FFA [Figure 2], but not always evident on trichoscopy for being an evolutive sign that is followed by interfollicular erythema [Figure 3]. We also found not visible vellus hairs between lonely hairs.[15] We have appreciated that in those patients whose FFA was in a progression phase, perifollicular erythema was more evident than in those the disease remained stationary, with statistical significance.

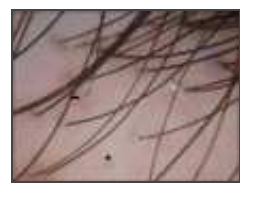

Figure 1

Trichoscopical findings in frontal fibrosing alopecia include absence of follicular openings (star), perifollicular hyperkeratosis (white arrow) and perifollicular erythema (black arrow). Perifollicular hyperkeratosis is better appreciated with the use ...

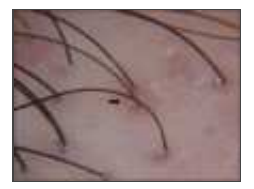

Figure 2

Perifollicular erythema is a characteristic feature of frontal fibrosing alopecia (black arrow)

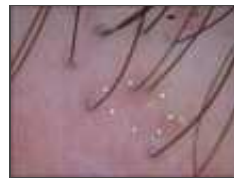

\section{Figure 3}

Perifollicular erythema (black arrow) it is not always evident on trichoscopy since it is an evolutive sign that is followed by interfollicular erythema (area delimited by white stars)

Thus, despite the diagnosis of FFA remains primarily clinical, we think that trichoscopy is a useful tool not only for differential diagnosis between FFA and other scarring alopecia, but also as an element to assess disease progression and response to treatment. From the present study, we conclude that the presence of perifollicular erythema will be a direct marker of disease activity.

\section{Footnotes}

\section{Source of Support: Nil}

Conflict of Interest: None declared.

\section{REFERENCES}

1. Kossard S, Shiell RC. Frontal fibrosing alopecia developing after hair transplantation for androgenetic alopecia. Int J Dermatol. 2005;44:321-3. [PubMed]

2. Moreno-Ramírez D, Ferrándiz L, Camacho FM. Diagnostic and therapeutic assessment of frontal fibrosing alopecia. Actas Dermosifiliogr. 2007;98:594-602. [PubMed]

3. Rudnicka L, Olszewska M, Rakowska A, Kowalska-Oledzka E, Slowinska M. Trichoscopy: A new method for diagnosing hair loss. J Drugs Dermatol. 2008;7:651-4. [PubMed]

4. Inui S. Trichoscopy for common hair loss diseases: Algorithmic method for diagnosis. J Dermatol. 2011;38:71-5. [PubMed]

5. Rubegni P, Mandato F, Fimiani M. Frontal fibrosing alopecia: Role of dermoscopy in differential diagnosis. Case Rep Dermatol. 2010;2:40-5. [PMC free article] [PubMed]

6. MacDonald A, Clark C, Holmes S. Frontal fibrosing alopecia: A review of 60 cases. J Am Acad Dermatol. 2012;67:955-61. [PubMed]

7. Inui S, Nakajima T, Shono F, Itami S. Dermoscopic findings in frontal fibrosing alopecia: Report of 
four cases. Int J Dermatol. 2008;47:796-9. [PubMed]

8. Mireles-Rocha H, Sánchez-Dueñas LE, Hernández-Torres M. Frontal fibrosing alopecia: Dermoscopic features. Actas Dermosifiliogr. 2012;103:167-8. [PubMed]

9. Rakowska A, Slowinska M, Kowalska-Oledzka E, Warszawik O, Czuwara J, Olszewska M, et al. Trichoscopy of cicatricial alopecia. J Drugs Dermatol. 2012;11:753-8. [PubMed]

10. Miteva M, Tosti A. The follicular triad: A pathological clue to the diagnosis of early frontal fibrosing alopecia. Br J Dermatol. 2012;166:440-2. [PubMed]

11. Inui S, Itami S. Emergence of trichoscopic yellow dots by topical corticosteroid in alopecia areata mimicking frontal fibrosing alopecia: A case report. J Dermatol. 2012;39:39-41. [PubMed]

12. Samrao A, Chew AL, Price V. Frontal fibrosing alopecia: A clinical review of 36 patients. Br J Dermatol. 2010;163:1296-300. [PubMed]

13. Inui S, Nakajima T, Itami S. Scalp dermoscopy of androgenetic alopecia in Asian people. J Dermatol. 2009;36:82-5. [PubMed]

14. Duque-Estrada B, Tamler C, Sodré CT, Barcaui CB, Pereira FB. Dermoscopy patterns of cicatricial alopecia resulting from discoid lupus erythematosus and lichen planopilaris. An Bras Dermatol. 2010;85:179-83. [PubMed]

15. Camacho FM. Lonely hair sign: Not specific for frontal fibrosing alopecia. Arch Dermatol. 2012;148:1208-9. 1209. [PubMed]

Articles from International Journal of Trichology are provided here courtesy of Medknow Publications 